\title{
Interações no ensino superior através da web 2.0: uma análise das condutas geradas no blog e youtube
}

Luciana de Lima Lemos

Maria Auxiliadora Soares Padilha

\section{Resumo}

Este artigo é parte de uma pesquisa realizada no cenário da Web 2.0 a partir da atuação de um professor universitário que ampliou as discussões de suas aulas presenciais em Blog e Youtube. A fim de verificar os tipos de condutas que ocorrem nas interações entre alunos e professores nessas interfaces, optamos em fazer uma pesquisa qualitativa e exploratória, além da análise do conteúdo das mensagens e publicações para identificarmos as condutas. A princípio objetivamos verificar as condutas de Pesquisa, Colaboração e Autoria, mas no decorrer desse estudo descobrimos outras, como as condutas Afetivas, Informativas e de Reflexão. Além disso, percebemos que essas condutas foram intensificadas de formas distintas, tanto no cenário do Blog quanto no do Youtube. Essa compreensão nos permitiu identificar uma relação complementar entre essas duas interfaces que favoreceu ao processo pedagógico online dos estudantes.

Palavras-chave: Blog; Youtube; Condutas; Interação.

\section{Abstract}

This article is part of a research conducted in the setting of Web 2.0 from the work of a university professor who expanded the discussions of their classroom lessons into Blog and Youtube. In order to check the types of behaviors that occur in the interactions among students and teachers on these interfaces, we chose to carry on a qualitative and exploratory research, and also performed a content analysis of messages and posts to identify the behaviors. At first we aimed at verifying Research, Collaboration and Authorship behaviors, but in the course of this study we found others, such as Affective, Informative and Reflexive behavior. Also, we realized that these behaviors were intensified in different ways, both in the case of Blog and on Youtube. This understanding has allowed us to identify a complementary relationship between these two interfaces that favored the online learning process of students.

Key words: Blog, Youtube, Behaviors; Interaction. 


\section{Introdução}

Diante de uma proposta de capacitação docente para uso de tecnologias da Web 2.0 no contexto do processo de ensino-aprendizagem em uma faculdade presencial privada no agreste pernambucano, identificamos um grupo de professores que utilizavam interfaces da Web (blogs, youtube, twitter) para complementar as discussões de sala de aula. Verificamos que essa proposta de interações na rede gerava discussões importantes para os alunos, gerando diferentes tipos de condutas de aprendizagem em seus estudantes a partir dessa estratégia online, complementar às aulas presenciais. Isso despertou o interesse em conhecermos o que esses professores estavam desenvolvendo nessas interfaces como estratégias de ensino-aprendizagem. Nosso interesse estava centrado no tipo de condutas que as atividades propostas pelo professor poderiam gerar nos alunos, para sua aprendizagem.

Sendo assim, tivemos como principal objetivo deste estudo verificar os tipos de condutas que ocorrem nas interações entre alunos e professores na Web 2.0, em específico nos cenários Blog e Youtube. A princípio gostaríamos de identificar apenas as condutas de Colaboração, Pesquisa e Autoria, por essas serem as mais presentes no processo de ensino e aprendizagem habitual. No entanto, no decorrer da pesquisa, verificamos a existência de outras, também importantes, que auxiliavam na proposta de construção do conhecimento a partir de comunidades virtuais, geradas e movimentadas pelos universitários e também presentes na educação presencial.

\section{Novos recursos tecnológicos para a educação: web 2.0}

A "comunicação humana mediada pelo computador para fins educativos levou a uma proliferação de tecnologias com o propósito de oferecer ambientes educativos on-line" (TELES, 2010, p. 72). Essa comunicação ampliou a capacidade de conexões e a relação entre as pessoas através das diversas redes constituídas na Web (RECUERO, 2009).

Nesse sentido, é comum identificarmos pessoas que "demonstram facilidades e interesse em assumir as inovações" (CARLONI e TARCIA, 2010, p. 28), pois a internet possibilita o alavancar de uma postura social e interrelacionista entre essas pessoas, que deixam de ser meras expectadoras para se tornarem protagonistas de suas ações na rede.

Belloni $(2008$, p.61) acredita que a educação deve "problematizar o saber, contextualizar os conhecimentos, colocá-los em perspectivas, para que os aprendentes possam aprimorar-se deles e utilizá-lo em outras situações", sendo necessário o despertar de alunos, professores e instituição para o uso de Tecnologias de Desenvolvimento da Informação e Comunicação (TDICs). 
Ao apresentar essas possibilidades de se relacionar com as informações na rede, discutimos o termo Web 2.0 pela forte evidência nos dias de hoje. Além disso, também resgataremos as peculiaridades que envolvem essas interfaces 2.0 no nosso estudo.

Romani e Kuklinski (2007, p.15) considera a Web 2.0 como um

fenômeno técnico-social que se popularizou a partir de suas aplicações mais representativas, Wikipédia, Youtube, Flickr, Word Press, Blogger, MySpace, Facebook, OhMynews, e da sobre-oferta de várias ferramentas inventadas para captar usuários/geradores de conteúdos.

Sendo assim, compreendemos que a Web 2.0 não se trata apenas de uma versão aprimorada da Web 1.0, que seria a própria internet. Na verdade, ela torna-se em 2006 (ROMANI; KUKLINSKI, 2007) um software social capaz de facilitar a colaboração e interação social (JORGE, 2009), ao possibilitar que qualquer usuário participe ativamente como produtor na Web de forma coletiva, ou melhor, colaborativa.

Nesse sentido, as tradicionais possibilidades de comunicação off-line evoluem para um mix de recursos que favorecem a comunicação off e online (MORAN, 2000) disponíveis em ambientes virtuais de aprendizagem colaborativos ou através das interfaces que favorecem "a participação, a intervenção, a bidirecionalidade e a multiplicidade de conexões" (SILVA, 2000, p.13).

A partir dessa perspectiva, além da tecnologia, a Web 2.0 se potencializa principalmente pela "inteligência coletiva" (LÉVY, 1999) tida como principal meio de atuação e disseminação da informação e do conhecimento. Por isso, inúmeras são as "possibilidades de autoria, partilha e construção colaborativa do conhecimento em espaços sociais, proporcionadas por essas ferramentas" (JORGE, 2009, p.18).

Para Moran (2000), Carloni e Tarcia (2010) e Netto (2005), o professor é o principal responsável pelas escolhas das ações educativas na internet. Cabe a ele criar situações de aprendizagem eficazes de forma mais "dinâmica, prazerosa e inovadora" (CARLONI; TARCIA, 2010, p.25) no processo de ensino e aprendizagem, evidenciando os alunos como "sujeitos pensantes, capazes de pensar e lidar com conceitos, argumentar, resolver problemas, para se defrontarem com dilemas e problemas da vida prática" (GIL, 2009, p. 5).

Desse modo, a Web 2.0 revolucionou a forma como as pessoas se relacionam e aprendem. Assim, compete ao professor

uma organização didática que explicite as relações entre as ferramentas, as funcionalidades das tecnologias da informação $e$ da comunicação e os objetivos pedagógicos que possibilitarão a construção de um todo sistêmico em 
suas partes, de modo a se configurar em situações diferenciadas de aprendizagem (CARLINI; TARCIA, 2010, p. 41).

Por isso, há necessidade desse professor assumir uma postura flexível no ambiente online, a fim de tornar-se um facilitador da aprendizagem de seus alunos, visto que ao propor utilizar os recursos da Web 2.0 sua função será de "fornecer indicações que orientem os aprendentes, facilitando ferramentas de comunicação, interação e partilha para o contexto poder evoluir" (JORGE, 2010, p. 39).

\section{Comunidades online na web 2.0}

As novas tecnologias possibilitam formas de ensino através de comunidades de aprendizagem. Essas são caracterizadas por "um conjunto de pessoas que se reúne em um espaço real e/ou virtual para interagir, trocar informações, discutir, buscando a construção de conhecimento a partir de objetivos comuns" (FARIA, 2006, p. 39).

Como uma comunidade representa o anseio de discussões e diálogos por pessoas que tenham os mesmos interesses, a comunidade virtual é composta por ferramentas flexíveis que apresentam diversificado número de recursos que favorecem o processo de interação entre os participantes, como também a busca por novos conhecimentos.

Para Palloff e Pratt (2002) "o poder de uma comunidade é grande. O poder de uma comunidade de aprendizagem é ainda maior, pois dá sustentação tanto ao crescimento intelectual quanto ao pessoal, e também a evolução de seus participantes" (p. 95). Desse modo, essas comunidades servem para "compartilhar a informação, os interesses e os recursos" pois são "parte integrante da educação on-line" (PALLOFF e PRATT, 2004, p. 38).

Diante disso, percebemos que as comunidades de aprendizagem na Web 2.0 favorecem o processo de comunicação entre os sujeitos/usuários. Elas se configuram mediante interfaces, como: Blogs, facebook, wikipédia, twiter, Youtube, dentre outras disponíveis na Web 2.0. Na pesquisa de mestrado que estamos realizando iremos analisar o uso dessas diversas interfaces, por professores do ensino superior e suas estratégias de ensino. Neste artigo, nos propomos a apresentar um recorte deste estudo, desenvolvido através do Blog e Youtube, a fim de verificar o despertar das condutas nos alunos durante o processo de ensino e aprendizagem online proposto por um professor universitário do ensino presencial. 


\section{Potencialidades do Blog}

Um Blog se caracteriza como "um diário com apontadores para outros sites, cuja função está organizada da mais recente para a mais antiga (em "post"), frequentemente atualizado com opiniões, fatos, imagens, etc" (CRUZ, 2008, p. 18).

Desse modo, definimos o Blog como um importante recurso educacional por possibilitar que alunos se expressem diante dos conteúdos, pois seu formato "permite que outros usuários possam intervir no conteúdo veiculado pelo autor" (SANTOS, 2003, p.13) e, assim, integrar conteúdos múltiplos de autoria dos próprios alunos.

Mattar (2012) ainda acrescenta que o Blog permite a "facilidade na criação e na publicação, a possibilidade de construção coletiva e o potencial de interação" (p.85). Entendemos, portanto, que o Blog seja uma interface que se configura através de recursos online, que possibilita o intercâmbio entre os usuários e seus seguidores. Com isso, o Blog é uma interface que desencadeia estratégias pedagógicas a partir de discussões coletivas de conteúdos, trabalho de atividades com desafios e, principalmente, é utilizado como portfólios digitais ou diários eletrônicos.

Para a educação, os Blogs se apresentam mais frequentemente como portfólios digitais ou diários eletrônicos. Nessa perspectiva, são considerados importantes recursos de comunidade de aprendizagem online, pois é, a partir dos diários, que os alunos registram toda a sua compreensão sobre os temas, fazem reflexões sobre o que foi proposto, compartilham vídeos, imagens e documentos. Enfim, possibilitam que "qualquer pessoa possa ser autora de sua própria tela" (CARLONI e TARCIA, 2010, p.33).

Diante disso, apresentamos a atuação pedagógica de um professor no Blog que integra, em suas publicações, videoaulas do Youtube. Por esse motivo é que também optamos por conhecer a interface Youtube, definindo-a a seguir para melhor compreensão desse estudo.

\section{Uma melhor compreensão do Youtube na educação}

Interface criada em 2005, o Youtube tem como objetivo "a partilha de vídeos" (CRUZ, 2008, p.25), e sua principal função é ser um repositório audiovisual de conteúdos autorais à disposição de qualquer pessoa.

Em 2008, o Youtube amplia as possibilidades de acesso e cria o 'Youtube Insight' que facilita o acesso público e detalhado sobre os vídeos publicados (CRUZ, 2008, p. 25).

Hoje praticamente qualquer um pode capturar, editar e compartilhar pequenos videoclips, utilizando equipamentos baratos (como celulares) e softwares gratuitos e livres. Sites de compartilhamento de vídeos têm crescido bastante, 
e o que costumava ser difícil e caro tornou-se algo que qualquer um pode realizar fácil e praticamente sem custo (MATTAR, 2012, p. 96).

Desse modo, o Youtube torna-se "o site mais popular para arquivamento e divulgação de vídeos e o mais acessado em pesquisas escolares" (CARLONI e TARCIA, 2010, p. 33).

Na educação, o Youtube serve como uma importante interface da Web 2.0 por permitir a dinamização e difusão de aulas. Por isso, quando usado para fins pedagógicos e didáticos, desperta a criatividade dos alunos possibilitando a construção de vídeos para trabalhos, seminários e/ou apresentações que são compartilhados e acessados por todos os usuários da rede.

Sobre o Youtube, Mattar (2012) afirma que através da inclusão de "comentários, respostas por vídeos e comunicação, disponíveis nessa plataforma, é possível transformá-la em ambiente virtual de aprendizagem" (MATTAR, 2012, p.94), visto que fica fácil visualizar as comunicações e interagir com os usuários da rede.

Nesse sentido, visualizamos como muitas as potencialidades do Youtube. Basta usar criatividade e objetividade para tornar essa interface um recurso de destaque para a educação online. Desse modo, pretendemos discutir através desse estudo como um professor usa essas potencialidades e assim destacar as particularidades do Youtube para educação.

\section{Definindo as condutas de Colaboração, Pesquisa e Autoria}

Para melhor definirmos o termo conduta recorremos ao dicionário Houaiss (2004) que relaciona esse termo ao comportamento. Diante dessa definição, caracterizamos conduta neste trabalho como sendo a forma de o aluno ser conduzido pelo professor no processo de ensino e aprendizagem de modo que suas estratégias didáticas facilitem e promovam condutas de Colaboração, Pesquisa e Autoria quando esses estiverem inseridos em atividades online utilizando as interfaces da Web 2.0.

Por isso, optamos em investigar como essas condutas podem estar relacionadas às propostas pedagógicas e ao comportamento dos sujeitos quando se deparam com interações online, já que essas interações despertam nos alunos um posicionamento quanto à seleção das escolhas dos conteúdos ou materiais de estudo na pesquisa online; possibilitam a colaboração entre os aprendentes, favorecendo o intercâmbio para troca de experiências, conteúdos e informações; como também favorecem recursos que estimulam a confeç̧ão e disseminação de conteúdos de autoria própria a fim de que os alunos assumam uma postura crítico-refexiva sobre os assuntos em evidência. 
Desse modo, iniciamos essa discussão caracterizando a conduta de Colaboração. Uma das mais importantes estratégias de aprendizagem na web, a colaboração é definida como sendo "um processo que ajuda os alunos a atingir níveis mais profundos de geração de conhecimento por meio da criação de objetivos comuns, trabalho conjunto e um processo compartilhado da produção de sentido" (PALLOFF e PRATT, 2004, p. 46).

Essa conduta se configura a partir de uma aprendizagem colaborativa que se potencializa mediante "apoio mútuo e o compartilhar de experiências" (FARIA, 2006, p.99), estabelecidas, na maioria das vezes, pelos aprendentes, que "colaboram com os demais e assumem uma responsabilidade crescente em seu próprio processo de aprendizagem" (TELES, 2009, p.72).

Por isso, destacamos que esse tipo de conduta na Web 2.0 requer do professor uma proposta pedagógica flexível a fim de incluir os anseios dos alunos durante a montagem do seu planejamento de atividades, deixando-os livres para discussões. Isso porque, na aprendizagem colaborativa, os professores devem "esperar que os alunos trabalhem juntos na produção de níveis de compreensão mais profundos e na avaliação crítica do material utilizado" (PALLOFF e PRATT, 2002, p.110).

Já na conduta de pesquisa, a internet favorece o compartilhar da informação de forma rápida, diversificada e acessível. Desse modo, Alava (2002) caracteriza a internet como sendo um livro sem fim que permite "a oportunidade de superar a clonagem de nossas antigas práticas de pesquisa e leitura informacional" (ALAVA, 2002, p.203), além de facilitar o acesso aos conteúdos na rede através de sites de buscas como Google, Yahoo, dentre outros.

Diante disso, a conduta de pesquisa se refere a quando se "estimula os alunos a serem investigadores, a buscarem em experiências, informações significativas e a analisá-las, individualmente ou em grupo, para teorizar" (MORAN, 2007, p.116). Afinal, na pesquisa, é importante o professor possuir um planejamento pedagógico que forneça roteiros de buscas seguros de modo que os alunos produzam suas próprias aprendizagens e, assim, particularizarem suas opiniões diante dos assuntos e conteúdos propostos pelo docente.

Assim, é fazendo uso das tecnologias de desenvolvimento da informação e comunicação (TDICS) que é comum identificar uma ressignificação dos conteúdos diante de novas autorias. Pois, a facilidade de acesso às informações ocasionou uma proposta pedagógica que possibilita os conteúdos serem reinterpretados de acordo com a percepção e estado consciente de cada aluno/autor (RAMAL, 2002).

Para isso, na conduta de autoria "a mensagem de um emissor assume novas formas à medida que circula no espaço socioideológico da outras consciências" (RAMAL, 2002, p.122), pois esse tipo de conduta permite o estímulo à expressão individual e crítico-reflexiva dos alunos. Cabe ao professor, portanto, propiciar atividades integradas que estimulem seus alunos a se 
posicionar, de acordo com a configuração cognitiva da informação, respeitando cada ponto de vista e estimulando-os a novos posicionamentos.

\section{A interação na web 2.0}

Como, no caso deste estudo, as condutas de Colaboração, Pesquisa e Autoria são geradas por interações no processo de ensino e aprendizagem online, discutimos, inicialmente, a interação a partir de suas características e especificidades no Blog e Youtube.

Segunda Almeida (1997), a interação "acontece quando duas pessoas ou mais entram em contato (não necessariamente contato físico) e ocorre uma mudança de comportamento" (p. 39). Para Mattar (2012) "a interação envolveria o comportamento e as trocas entre indivíduos e grupos que se influenciam, nos casos em que há eventos recíprocos que requerem pelo menos dois objetos e duas ações" (p.25).

Contudo, Silva (2002, p.69) afirma que "comunicar não é simplesmente transmitir, mas disponibilizar múltiplas disposições à intervenção do interlocutor. A comunicação só se realiza mediante a sua participação". Desse modo, é relevante destacar a importância da atuação do professor para escolher estratégias de ensino e guiar seus alunos neste processo imerso nas TDICs.

Diante desse processo, que propõe um diálogo entre os usuários (professor e alunos) num espaço virtual, compreendemos que além das tecnologias interativas produzirem grande impacto na sociedade (TORI, 2009), o processo de interação é um importante condutor da comunicação nas condutas de Colaboração, Pesquisa e Autoria, ao favorecer uma aproximação das relações educativas, quando optamos pelas interfaces na Web 2.0.

\section{Metodologia}

Considerando que o objetivo desse estudo é verificar os tipos de condutas que ocorrem nas interações entre alunos e professores em interfaces da Web 2.0, especificamente Blog e Youtube, optamos por uma pesquisa de natureza qualitativa do tipo explicativa, por essa possibilitar um aprofundamento e uma identificação mais minuciosa dos conteúdos a serem analisados.

Como os dados de pesquisa identificados e analisados acontecem no cenário da Web 2.0, local onde incidem as interações e atividades propostas pelo docente, decidimos utilizar a observação online para nos auxiliar na coleta de dados, visto que será a partir da análise das discussões geradas nos cenários Blog e Youtube, que utilizaremos esse método de pesquisa para nos auxiliar numa investigação profunda das interações ocorridas nessas interfaces. 
Segundo Cervo et al (2007, p.31) a observação visa "aplicar atentamente os sentidos físicos a um objeto para dele obter um conhecimento claro e preciso". É um instrumento de coleta que "deve ser sempre uma atividade capaz de conduzir a um aprendizado ativo com uma postura dirigida para um determinado fato" (FACHIN, 2006, p.38).

Para análise dos dados coletados na observação das interfaces utilizamos a análise de conteúdos $(\mathrm{AC})$, que é "um conjunto de técnicas de análise das comunicações, que utiliza procedimentos sistemáticos e objetivos de descrição do conteúdo das mensagens" (BARDIN, 1997, p.38), para seleção e verificação de todo o material recolhido, principalmente para verificarmos as condutas que selecionamos a priori para esse estudo: Colaboração, Pesquisa e Autoria. Da mesma forma, utilizaremos a AC para identificarmos as outras condutas que envolveram o processo pedagógico online do professor DF com seus alunos nas interfaces Blog e Youtube.

\section{Resultados e discussões: cenários Blog e Youtube}

Para esse estudo tivemos como sujeito o professor "DF" da disciplina Algoritmos de uma faculdade presencial de Pernambuco, que atuava no semestre 2011.1, em duas turmas do Curso de Análise e Desenvolvimento de Sistemas (Turma A e B) e uma turma de Rede de Computadores, onde resultavam mais de cem estudantes. No entanto, não foi feita uma análise do perfil de uso das interfaces desses alunos, visto que nosso interesse era perceber que conduta a ação do professor gerava no aluno, especificamente na situação de ensino e aprendizagem daquela disciplina, independente da experiência desses alunos com as interfaces. Também é importante destacar que esse professor foi escolhido, especialmente, porque usava essas interfaces já há algum tempo em suas disciplinas.

Além do Blog, esse professor também utilizou um ambiente online com a criação de vídeoaulas no Youtube para explorar mais seus conteúdos com seus alunos, integrando esse recurso para uma melhor explicação do que ocorria no Blog (Figura 1). 


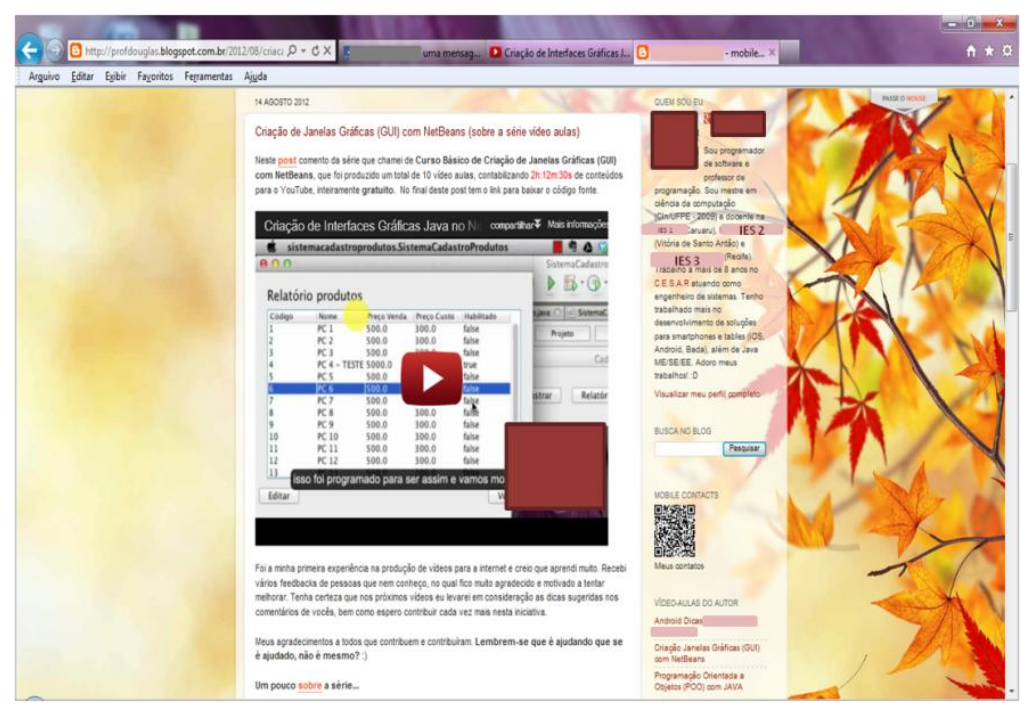

Figura 1 - videoaulas do Youtube disponíveis e integradas ao Blog

(Fonte: Registro do autor /2012)

Como o uso do Blog no âmbito educacional permite a "facilidade na criação e na publicação, a possibilidade de construção coletiva e o potencial de interação" (MATTAR, 2012,p.85), visto que é uma interface que se configura como um recurso que possibilita o intercâmbio entre o autor, seus usuários e seguidores, todas as estratégias desenvolvidas nele dependem da forma criativa e planejada do autor em sua atuação e disponibilização para tratar os conteúdos.

Diante dessas características, constatamos através da imersão nesse cenário da Web 2.0, que o $\operatorname{Blog}^{1}$ do professor DF foi criado em 2007, porém apenas em 2011 e 2012 foi que o docente integrou as videoaulas à sua proposta de atuação online, quando percebeu uma maior participação dos seus alunos e outros interessados nos conteúdos que disponibilizava através desta interface.

Para este estudo, analisamos justamente o período em que as postagens do professor estavam vinculadas às suas aulas. Através da coleta de dados pela observação online e o tratamento desses dados a partir da análise do conteúdo (MORAES, 1999) verificamos dezessete publicações e treze comentários. Isso permitiu conhecermos as condutas geradas pelo docente e usuários na interface, através dessas publicações e comentários.

Para uma melhor visualização dessas condutas formatamos a tabela 1 com as unidades de sentido e as intensidades (em \%) que remetem a cada tipo de conduta. Destacamos também as condutas que foram tratadas nas publicações do docente (na cor laranja) e aquelas geradas a

\footnotetext{
${ }^{1}$ Disponível em: <http://profdouglas.Blogspot.com.br/>
} 
partir das mensagens e comentários verificados e postos em cena pelos alunos/interessados no Blog (na cor verde).

Apesar de haver apenas treze comentários de alunos e interessados nesses dois anos de análise, estes serviram para que pudéssemos analisar os tipos de condutas que foram geradas por esses atores e pelo diretor da aprendizagem nessa interface. Ressaltamos que o professor utilizava também outras interfaces, como facebook e twiiter, que foram analisadas em outro estudo (LEMOS,2013). Dessa forma, podemos entender que as atividades, nas diversas interfaces, se complementavam e, por isso, acreditamos, houve uma intensidade menor de comentários no Blog.

As condutas de Colaboração, Autoria e Pesquisa foram definadas como categorias a priori, ou seja, definidas a partir dos objetivos da investigação. Após uma análise mais aprofundada dessas interações e a definição das unidades de sentido, identificamos outras categorias, como a afetiva, a informativa e a de reflexão. Todas essas categorias estão explicitadas nas tabelas 1 e 2.

Quanto à intensidade das condutas geradas pelo professor DF, destacamos no Blog as condutas de Autoria (40\%), Pesquisa (15\%), Informativa Acadêmica (16\%) e de Reflexão (20\%). Já para os comentários dos alunos/interessados, observamos as condutas de Colaboração (47\%) e Afetiva Pessoal (20\%). Isso nos ajuda a compreender a disparidade quanto à intensidade e existência das condutas verificadas nessa interface (Tabela 1).

Ressaltamos ainda que em meio à verificação das publicações, constatamos o encontro de duas ou três condutas. Com isso, compreendemos que o professor DF soube tratar de forma variada os conteúdos nesse cenário. Então, verificamos uma variação das condutas geradas por suas publicações, despertando assim qualquer ação ou resposta daquelas pessoas interessadas no seu material. 
Tabela 1 - Condutas e as unidades de sentido no Blog

\begin{tabular}{|c|c|c|c|c|c|}
\hline \multirow{2}{*}{$\begin{array}{l}\text { CATEGORIAS } \\
\text { (CONDUTAS BLOG) }\end{array}$} & \multirow{2}{*}{ SUBCATEGORIAS } & \multicolumn{2}{|c|}{$\begin{array}{l}\text { UNIDADES DE SENTIDO - Ações que } \\
\text { manifestam as condutas. }\end{array}$} & \multicolumn{2}{|c|}{ MSG (\%) } \\
\hline & & Alunos / Outros & Professor & $\begin{array}{c}\text { Comentários } \\
\text { (alunos/ } \\
\text { interessados) }\end{array}$ & $\begin{array}{l}\text { Prof. } \\
\text { DF } \\
\text { (Post) }\end{array}$ \\
\hline COLABORAÇÃO & & $\begin{array}{l}\text { Discussões; } \\
\text { complementação do } \\
\text { conteúdo } \\
\text { apresentado no } \\
\text { post. }\end{array}$ & $\begin{array}{l}\text { Respostas e } \\
\text { complementação } \\
\text { das explicações } \\
\text { dos conteúdos. }\end{array}$ & $47 \%$ & $8 \%$ \\
\hline AUTORIA & & & $\begin{array}{l}\text { Explicações de } \\
\text { conteúdo; } \\
\text { disponibilização de } \\
\text { aulas. }\end{array}$ & $0 \%$ & $40 \%$ \\
\hline PESQUISA & & & $\begin{array}{l}\text { Estímulo à prática } \\
\text { para resolução de } \\
\text { exercícios e } \\
\text { programas }\end{array}$ & $0 \%$ & $15 \%$ \\
\hline \multirow[t]{2}{*}{ AFETIVA } & PESSOAL & $\begin{array}{l}\text { Expressões pessoais; } \\
\text { críticas; } \\
\text { agradecimentos. }\end{array}$ & $\begin{array}{l}\text { Expressões } \\
\text { pessoais; } \\
\text { agradecimentos. }\end{array}$ & $20 \%$ & $4 \%$ \\
\hline & MOTIVAÇÃO & $\begin{array}{l}\text { Elogios; frases de } \\
\text { otimismo. }\end{array}$ & $\begin{array}{l}\text { Elogios; incentivo } \\
\text { aos alunos na } \\
\text { profissão e na } \\
\text { área. }\end{array}$ & $13 \%$ & $8 \%$ \\
\hline \multirow[t]{2}{*}{ INFORMATIVA } & $\begin{array}{l}\text { INFORMATIVA } \\
\text { INSTITUCIONAL }\end{array}$ & $\begin{array}{l}\text { Despertar } \\
\text { informações sobre o } \\
\text { curso e Instituição. }\end{array}$ & $\begin{array}{l}\text { Informações sobre } \\
\text { o curso e IES em } \\
\text { que o professor } \\
\text { trabalha. }\end{array}$ & $13 \%$ & $4 \%$ \\
\hline & $\begin{array}{l}\text { INFORMATIVA } \\
\text { ACADÊMICA }\end{array}$ & & $\begin{array}{l}\text { Informações sobre } \\
\text { a profissão; } \\
\text { materiais ou } \\
\text { programas } \\
\text { referentes ao } \\
\text { curso ou área. }\end{array}$ & $0 \%$ & $16 \%$ \\
\hline REFLEXÃO & & $\begin{array}{l}\text { Posicionamentos; } \\
\text { argumentações. }\end{array}$ & $\begin{array}{l}\text { Questões ou } \\
\text { perguntas de } \\
\text { reflexão sobre o } \\
\text { tema. }\end{array}$ & $6,5 \%$ & $20 \%$ \\
\hline
\end{tabular}

(Fonte: elaborada pelo autor/2012)

$\mathrm{Na}$ análise do Blog do professor, aquelas condutas propostas a priori para esse estudo, como a Colaboração, Autoria e Pesquisa, estavam presentes na proposta do docente, porém com intensidades distintas. No caso dessa interface, a Autoria foi a conduta que deteve uma maior intensidade nas publicações. Isso com relação a todas às outras. Já a conduta de Colaboração foi a mais gerada nos comentários dos alunos desse cenário (Tabela 1). 
Para melhor verificarmos essa atuação integrada, vamos à análise da interface Youtube. Como sabemos que o Youtube tem a função de repositório audiovisual de conteúdos autorais à disposição de qualquer pessoa por dispor de "recursos como comentários, respostas por vídeos e comunicação" (MATTAR, 2012, p.96), tendemos a perceber que essa seria uma interface provida de interação.

Sendo assim, para compreendermos melhor essa atuação do professor DF no Youtube, analisamos todos os comentários dos usuários que compuseram essa interface (alunos/interessados/professor), e as publicações das videoaulas ocorridas durante todo o ano de 2012.

Para isso, identificamos 22 videoaulas ${ }^{1}$, que foram divididas pelo professor DF em três grupos de aulas sequenciadas no Youtube, intituladas como: Curso Básico - criação janelas gráficas (11 publicações); Programação Orientada para Objeto - POO (7 publicações); e Android Dicas (4 publicações).

Salientamos ainda que até a data dessa análise tínhamos um registro de 451 inscritos e 52.641 exibições. Dessas, $30.265(57,5 \%)$ corresponderam ao período em que estiveram disponíveis esses três grupos de aulas online, de maio a setembro de 2012. Nesse mesmo período também registramos que foram gerados 239 comentários, distribuídos nas 22 videoaulas do canal do professor DF (Figura 2).

Diante desses registros, nossa análise se restringiu a esse momento em que o professor DF propôs uma atividade online, a partir dessas criações de videoaulas no cenário Youtube. Neste, identificamos as condutas que foram intensificadas pelo docente na sua proposta de aula online, como também aquelas condutas geradas, através dos comentários dos alunos e interessados.

Como "ensinar utilizando a internet exige uma forte dose da atenção do professor" (MORAN, 2008, p.52), constatamos que a atuação do docente no cenário Youtube se desencadeou a partir dos feedbacks dos comentários e perfil do seu público. Um exemplo disso foi quando o professor identificou um aluno surdo-mudo em sua turma e, diante dessa descoberta, passou a utilizar legendas em suas videoaulas.

${ }^{1}$ Disponível em: <http://www.Youtube.com/user/douglasddf/videos?view=1\&flow=grid> 


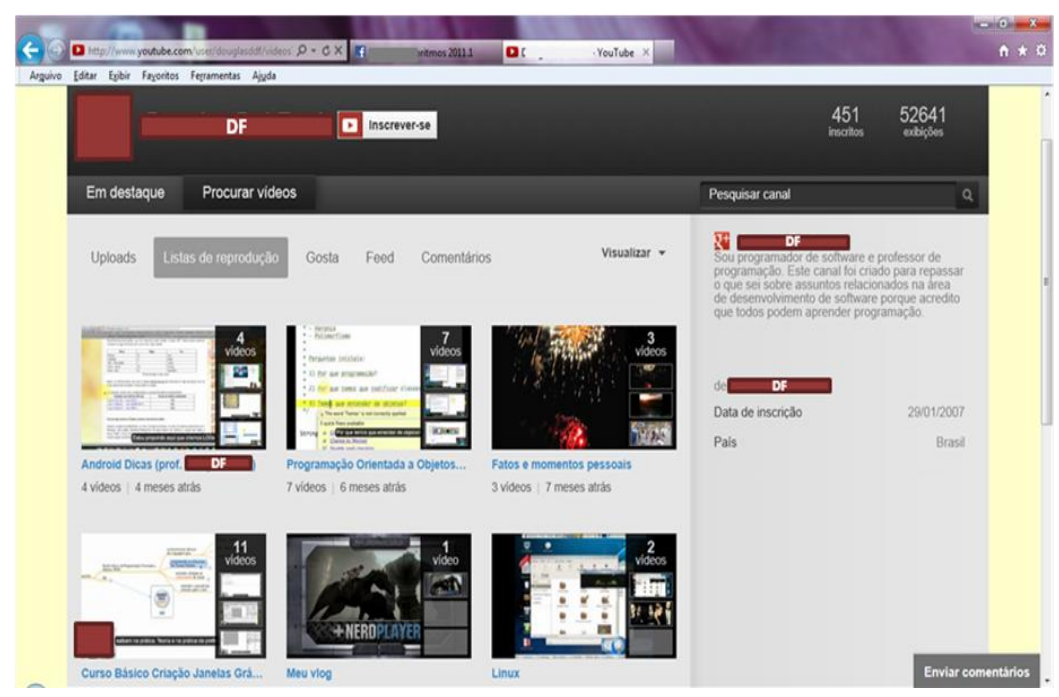

Figura 2 - Cenário Youtube (Professor DF)

Fonte: Registro do autor $/ 2012$

Com isso, ao interpretarmos todos esses dados, restringimo-nos a identificar aquelas condutas que destacamos a priori para esse estudo, como a Colaboração, a Autoria e a Pesquisa, quando percebemos que nesse cenário a conduta de Autoria não foi contemplada diante de uma proposta pedagógica funcional. Ou seja, mesmo sendo o Youtube uma interface que desencadeia a produção de videoaulas, não definimos como sendo essa a unidade de sentido referente à conduta de Autoria, desde que a própria interface tem como característica essa criação autoral e em seu bojo já apresenta características específicas a essa interface.

Nesse contexto, passamos a analisar o teor dessas publicações e comentários, e então percebemos através da tabela 2 que a proposta online do docente (na cor laranja) desencadeou, nos alunos, maior intensidade na conduta de Pesquisa (95\%) e muito pouco na conduta de Reflexão (5\%), gerando mais comentários de Motivação $(45,5 \%)$ por parte dos alunos/interessados (marcados com a cor verde).

Ao analisarmos as intensidades dos comentários do professor DF (na cor laranja), foram geradas mais condutas de Colaboração (14\%). Nos alunos/interessados (na cor verde) nas videoaulas foram geradas as condutas Afetiva de Motivação (45,5\%) e Afetiva Pessoal (14\%). 
Tabela 2 - Condutas e as unidades de sentido no cenário Youtube

\begin{tabular}{|c|c|c|c|c|c|c|}
\hline \multirow{2}{*}{$\begin{array}{l}\text { CATEGORIAS } \\
\text { (CONDUTAS } \\
\text { YOUTUBE) }\end{array}$} & \multirow[b]{2}{*}{ SUBCATEGORIAS } & \multicolumn{2}{|c|}{$\begin{array}{l}\text { UNIDADES DE SENTIDO - Ações que } \\
\text { manifestam as condutas. }\end{array}$} & \multicolumn{2}{|c|}{$\begin{array}{c}\text { MSG (\%) } \\
\text { Comentários }\end{array}$} & \multirow{2}{*}{$\begin{array}{c}\text { Publicações } \\
\text { Prof. DF }\end{array}$} \\
\hline & & $\begin{array}{c}\text { Alunos/ } \\
\text { Interessados }\end{array}$ & Professor & $\begin{array}{c}\text { Usuários } \\
\text { (alunos/ } \\
\text { interessados) }\end{array}$ & $\begin{array}{l}\text { Prof } \\
. \mathrm{DF}\end{array}$ & \\
\hline COLABORAÇÃO & & $\begin{array}{l}\text { Ajuda; } \\
\text { Questionamentos } \\
\text {; } \\
\text { Complementaçõe } \\
\text { s sobre o assunto. }\end{array}$ & $\begin{array}{l}\text { Explicações; } \\
\text { Respostas; } \\
\text { Diálogo. }\end{array}$ & $10 \%$ & $14 \%$ & $0 \%$ \\
\hline PESQUISA & & $\begin{array}{l}\text { Prática (dispor de } \\
\text { resoluções e } \\
\text { aplicações de } \\
\text { problemas) }\end{array}$ & $\begin{array}{l}\text { Aulas ensinando } \\
\text { como utilizar e } \\
\text { manusear } \\
\text { programas. }\end{array}$ & $1,5 \%$ & $0 \%$ & $95 \%$ \\
\hline AUTORIA & & & & $0 \%$ & $0 \%$ & $0 \%$ \\
\hline \multirow[t]{2}{*}{ AFETIVA } & PESSOAL & $\begin{array}{l}\text { Saudações; } \\
\text { Críticas; } \\
\text { Sugestões; } \\
\text { Informações } \\
\text { Pessoais. }\end{array}$ & $\begin{array}{l}\text { Saudações; } \\
\text { Críticas; } \\
\text { Sugestões; } \\
\text { Informações } \\
\text { Pessoais. }\end{array}$ & $14 \%$ & $7 \%$ & $0 \%$ \\
\hline & MOTIVAÇÃO & $\begin{array}{l}\text { Elogios; } \\
\text { Agradecimentos. }\end{array}$ & $\begin{array}{l}\text { Elogios; } \\
\text { Agradecimentos. }\end{array}$ & $45,5 \%$ & $8 \%$ & $0 \%$ \\
\hline REFLEXÃO & & & $\begin{array}{l}\text { Perguntas; } \\
\text { Levantar } \\
\text { questionamentos. }\end{array}$ & $0 \%$ & $\%$ & $5 \%$ \\
\hline
\end{tabular}

(Fonte: elaborada pelo autor/2012)

\section{Considerações}


Como já apresentamos que o Blog possibilita a conexão de vídeos, imagens e texto, e o Youtube ocasiona uma dinamização da aula online, verificamos, ao analisarmos no Blog e Youtube as publicações e as interações das mensagens, que cada cenário favorece condutas específicas que, em geral, estão relacionadas às características e funcionalidades da interface.

Por isso, constatamos que houve uma complementaridade na proposta de aula do docente nessas duas interfaces: Blog e Youtube. As aulas online do professor "DF" tiveram destaques na medida em que se tornaram visualmente mais atrativas e dinâmicas, favorecendo a sua apresentação para com os alunos/interessados aos temas disponíveis.

Com isso, observamos que cada interface ocasiona condutas específicas e, quando relacionadas, desencadeiam-se para resultados mais significativos na proposta de aquisição do conhecimento para a educação.

Assim, os resultados dessa pesquisa serviram para verificarmos uma importante hipótese: o tipo da interface pode influenciar nas condutas geradas pelos alunos a partir das estratégias indicadas pelos professores. Dessa forma, um Blog, por suas características que possibilitam ao usuário fazer seu próprio diário digital e assim expor pontos de vistas pessoais, promoveu mais condutas de autoria por parte do professor. Já no Youtube, identificamos mais condutas Afetivas por parte dos usuários/alunos, de modo que nessa interface não houve muitas discussões referentes aos temas propostos. Entretanto, esse resultado nos mostrou que essa integração entre as interfaces é essencial para o desenvolvimento de um processo pedagógico online dinâmico na Web 2.0.

\section{Referências}

ALAVA, Séraphin. Ciberespaço e formações abertas: rumo a novas práticas educacionais. Porto Alegre: Artmed, 2002.

ALMEIDA, Antônio. Comunicação interativa em EAD. Tecnologia educacional. Rio de Janeiro, ano 25, n. 139, p. 39-41, nov/dez, 1997.

BARDIN, Laurence. Análise de Conteúdo. Lisboa: Edições 70, 1997.

BELLONI, Maria Luiza. Educação a Distância. 5a Edição. Campinas, SP: Autores Associados, 2008

CARLONI, Alda Luiza; TARCIA, Rita Maria Lino. 20\% a distância: e agora?: orientações práticas para o uso de tecnologia de educação a distância no ensino presencial. São Paulo: Pearson Education do Brasil, 2010.

CERVO, Amado Luiz; BERVIAN, Pedro Alcino; SILVA, Roberto de. Metodologia científica -6. EdSão Paulo: Pearson Prentice Hall, 2007. 
CRUZ, Sónia. Blogue, Youtube. In: CARVALHO, Ana Amélia A. (Org). Manual de Ferramentas da Web 2.0 para professores. Ministério da Educação, 2008.

FACHIN, Odília. Fundamentos de Metodologia. 5ạ Ed. São Paulo: Saraiva, 2006.

FARIA, Elaine Turk (Org.). Educação Presencial e Virtual: espaços complementares essenciais na escola e na empresa. Porto Alegre: EDIPUCRS, 2006.

GIL, Antonio Carlos. Didática do Ensino Superior - 1. Ed. - 4. Reimpr. - São Paulo: Atlas, 2009. HOUAISS, Antônio (org). Minidicionário Houaiss da língua portuguesa. - 2. Ed. ver. e aum. - Rio de Janeiro: Editora Objetiva 2004.

JORGE, Nelson Ribeiro. Contexto de aprendizagem 2.0: a utilização de ferramentas 2.0 para uma aprendizagem em contexto. Dissertação do Mestrado em Ciências da Educação, com especialidade em pedagogia do elearning - Universidade Aberta. Lisboa, 2009. Disponível em <http://repositorioaberto.univ-ab.pt/handle/10400.2/1380>. Acesso em: 20 de março, 2011. LEMOS, Luciana de Lima. Coreografias didáticas on-line no ensino superior: possibilidades de colaboração, pesquisa e autoria utilizando interfaces da web 2.0. 2013. 181f. Trabalho de conclusão de curso - Pós-graduação em Educação Matemática e Tecnológica (Mestrado em EDUMATEC). Universidade Federal de Pernambuco - UFPE. Recife, PE. Disponível em: < http://www.ufpe.edumatec.net/index.php?option=com_phocadownload\&view=category\&id=11: educacao-tecnologica\&Itemid=87>

LÉVY, Peirre. Cibercultura. 1ạ ed. São Paulo: 34, 1999.

MATTAR, João. Tutoria e interação em educação a distância. - São Paulo: Cengage Learning, 2012 (Série Educação e Tecnologia).

MORAES, Roque. Análise de conteúdo. In: Revista Educação, Porto Alegre, v. 22, n. 37. 1999. Disponível em: <http://www.letraviva.net/arquivos/tcc/5-\%20Roque_Moraes.pdf>. Acesso em: 14 de janeiro 2013.

MORAN, José Manuel. A educação que desejamos: Novos desafios e como chegar lá. - Campinas, SP: Papirus, 2007.

Ensino e aprendizagem inovadores com tecnologias audiovisuais e telemáticas. In: MORAN, José Manuel; MASETTO, Marcos T; BEHRENS, Marilda Aparecida. Novas tecnologias e mediação pedagógica. Campinas, SP: Papirus, 2000.

NETTO, Alvim Antônio de Oliveira. Novas Tecnologias \& Universidade: da didática tradicionalista à inteligência artificial: desafios e armadilhas. Petrópolis, RJ: Vozes, 2005. 
PALLOFF, Rena M.;PRATT, Keith. Construindo comunidade de aprendizagem no ciberespaço: estratégias eficientes para a sala de aula on-line. [trad. Vinícius Figueira]. Porto Alegre: Artmed, 2002.

. O aluno virtual: um guia para trabalhar com estudantes on-line. [trad. Vinícius Figueira]. Porto Alegre: Artmed, 2004.

RAMAL, Andrea Cecília. Educação na cibercultura: hipertextualidade, leitura, escrita e aprendizagem. - Porto Alegre: Artmed, 2002.

RECUERO, Raquel. Redes sociais na internet - Porto Alegre: Sulina, 2009.

ROMANÍ, Cristobal Cobo; KUKLINSKI, Hugo Pardo. Planeta Web 2: Inteligencia colectiva o medios fast food. Grup de recerca d'Interaccions digitais. Universitat de Vic. Flacso México. Barcelona/ México DF. 2007.

SANTOS, Edméa Oliveira. Ambiente virtuais de aprendizagem: por autorias livres, plurais e gratuitas. In: Revista FAEBA, v. 12, no. 18. 2003. Disponível em:

$<$ http://www.comunidadesvirtuais.pro.br/hipertexto/home/ava.pdf $>$. Acesso em: 03 de fevereiro de 2012.

SILVA, Marcos. Sala de aula Interativa. Rio de Janeiro: Quartet, 2000.

TELES, Lucio. A aprendizagem por e-learning. In: LITTO, Frederic Michael; FORMIGA, Manuel Marcos Maciel (Orgs.). Educação a Distância: o estado da arte. São Paulo: Pearson Education do Brasil, 2009.

TORI, Romero. Cursos híbridos ou blended learning. In: LITTO, Frederic Michael; FORMIGA, Manuel Marcos Maciel (Orgs.). Educação a Distância: o estado da arte. São Paulo: Pearson Education do Brasil, 2009.

Luciana de Lima Lemos - Graduada em Comunicação Social com Habilitação em Publicidade e Propaganda pela FAVIP (2005); Especialista em Marketing pela FAVIP (2007), em Educação a Distância pelo SENAC (2008) e concluindo a especialização em Metodologias e Didática da EAD (Anhanguera Educacional - 2012). Em 2013 concluí o Mestrado em Educação Tecnológica através do Programa de Pós-graduação em Educação Matemática e Tecnológica da UFPE. luciana.evolua@gmail.com

Maria Auxiliadora Soares Padilha - Possui graduação em Pedagogia (1997), mestrado em Educação (2001) e doutorado em Educação pela Universidade Federal de Pernambuco (2006). 